\title{
Childhood Brain Glioblastoma
}

National Cancer Institute

\section{Source}

National Cancer Institute. Childhood Brain Glioblastoma. NCI Thesaurus. Code C147901.

A brain glioblastoma that occurs during childhood. 